\title{
Analisis Partial Least Square Menghasilkan Output Alternatif Antarmuka Tambahan Dari Kansei Engineering
}

\author{
Arief Ginanjar \\ Fakultas Teknik \\ Program Studi Informatika \\ Universitas Langlangbuana \\ Jl. Karapitan 116, Bandung \\ arief.ginanjar@unla.ac.id
}

\author{
Awan Setiawan \\ Fakultas Teknik \\ Program Studi Teknik Industri \\ Universitas Langlangbuana \\ Jl. Karapitan 116, Bandung \\ awans2425@gmail.com
}

\begin{abstract}
Abstrak - Ketika menggunakan Kansei Engineering dalam mencari kandidat terbaik untuk menentukan model perancangan antarmuka website, peneliti menggunakan metode analisis Partial Least Square (PLS) yang dilakukan secara berulang hingga ditemukan elemen terbaik yang dapat diimplementasikan. PLS sebagai alat bantu untuk menentukan nilai terbaik antara elemen website. Output perbandingan yang dihasilkan akan dikelompokkan berdasarkan Kansei Word sebagaimana yang telah ditentukan dalam rencana awal implementasi Kansei Engineering, output perbandingan PLS iterasi pertama mempunyai kemungkinan mendapatkan nilai usulan terbaik jika digabung dengan melakukan iterasi kedua terhadap asimilasi dua atau tiga elemen yang mempunyai nilai tertinggi. Metodologi yang digunakan mengacu kepada Kansei Engineering Type I dengan melalui pengolahan data menggunakan Cronbach's Alpha untuk menguji kelayakan responden, kemudian untuk mengetahui hubungan Kansei Words dapat menggunakan Coefficient Correlation Analysis (CCA), sedangkan hubungan antara Kansei Words dengan spesimen dapat menggunakan Principal Component Analysis (PCA), sedangkan mencari pengaruh Kansei Words paling kuat dapat menggunakan Factor Analysis (FA) dan analisis Partial Least Square (PLS) namun harus dilakukan iterasi proses PLS hingga variabel rekomendasi model perancangan antarmuka yang dihasilkan menjadi lebih bervariatif.
\end{abstract}

Kata kunci - Desain Website, Kansei Engineering, Kansei Word, Partial Least Square

\section{PENDAHULUAN}

\subsection{Latar Belakang}

Kansei Engineering atau Kansei Ergonomic dalam dunia industri sebenarnya sudah dimulai pada tahun 1970 dengan penelitian yang dilakukan terhadap produk yang dimiliki perusahaan kelas dunia yaitu Mazda, Sharp dan Wacoal, namun kombinasi Kansei Engineering dengan pengembangan perangkat lunak baru dimulai sekitar tahun 2007 ketika peneliti dari Malaysia mulai melakukan penelitian terhadap salah satu cabang disiplin ilmu dalam pengembangan perangkat lunak yaitu Interaksi Manusia dan Komputer menggunakan pendekatan Kansei Engineering [6]. Hingga saat ini masih banyak para pelaku industri perangkat lunak yang merencanakan perancangan antarmuka sistem website yang subjektif menurut perasaan pemilik perangkat lunak bukan berdasarkan perasaan survey terhadap calon pengguna perangkat lunak.

Dalam penelitian yang sudah dilakukan sebelumnya telah diketahui bahwa kelompok responden dibagi menjadi tiga macam yaitu partisipan tanpa melihat jenis kelamin, partisipan laki-laki dan kelompok partisipan perempuan [1]. Meskipun secara perkembangan metodologi Kansei Engineering sudah mencapai delapan jenis metode untuk mencari nilai Kansei [7], namun penelitian yang dilakukan ini masih fokus terhadap metodologi jenis pertama yaitu mengklasifikasikan kategori menggunakan tahapan proses statistik untuk mengetahui perasaan calon pengguna sistem atau perangkat lunak melalui survey. Kansei Engineering sendiri memiliki metode khusus untuk menganalisa kebutuhan serta perasaan konsumen dan menerapkan terhadap perancangan dan karakter suatu produk[2][4].

Partial Least Square (PLS) merupakan salah satu teknik statistik multivariat seperti SEM yang mempunyai fungsi untuk menangani variabel respon dan variabel eksplanatori sekaligus, namun keistimewaan lain dari PLS dapat melakukan analisis hanya dengan menggunakan sampel yang sedikit [5].

\subsection{Tujuan Penelitian}

Adapun tujuan yang diharapkan dari kegiatan penelitian ini adalah:

Mengetahui tahapan yang harus dilakukan dalam mencari nilai alternatif tambahan perancangan desain tampilan website pendekatan Kansei Engineering menggunakan Partial Least Square.

Menghasilkan alternatif rekomendasi baru dalam penggunaan elemen perancangan desain website yang dihasilkan melalui pendekatan Kansei Engineering.

\subsection{Batasan Masalah}

Dalam penelitian ini penulis mencoba menerapkan batasan masalah sebagai berikut: 
Penelitian yang dilakukan merupakan bagian dari proses analisis Kansei Engineering menggunakan Kansei Engineering Type I atau Kansei Engineering Category Classification.

Asimilasi nilai Kansei Word baru dihasilkan dari dua Kansei Word tertinggi iterasi pertama yang digabungkan melalui proses Partial Least Square.

Sumber data Kansei Word merupakan data questioner dari orang tua yang mempunyai anak dan mengerti dan dapat berinteraksi dengan dunia internet dan website.

\section{METODE PENELITIAN}

Peneltian yang dilakukan berdasarkan atas penelitian yang telah dilakukan sebelumnya menggunakan Kansei Engineering yang merupakan kerangka kerja penelitian aspek emosional dalam perancangan antarmuka sistem informasi berbasis web berdasarkan disiplin ilmu matematika, statistik, psikologi dan teknik informatika [3][4]. Kansei diambil dari istilah bahasa Jepang yang digunakan untuk mengekspresikan kesan seseorang terhadap objek, situasi dan lingkungan sekitar. Dengan berakar kuat pada budaya Jepang, terjemahan langsung kata Kanseito agak sulit. Memiliki berbagai interpretasi dari berbagai literatur, Kansei umumnya mengacu pada sensitivitas, kepekaan, perasaan dan emosi [2] [6].

Metode yang digunakan dalam penelitian ini mengacu pada Kansei Engineering Type I lebih fokus kepada PLS seperti yang terlihat pada Gambar 1.

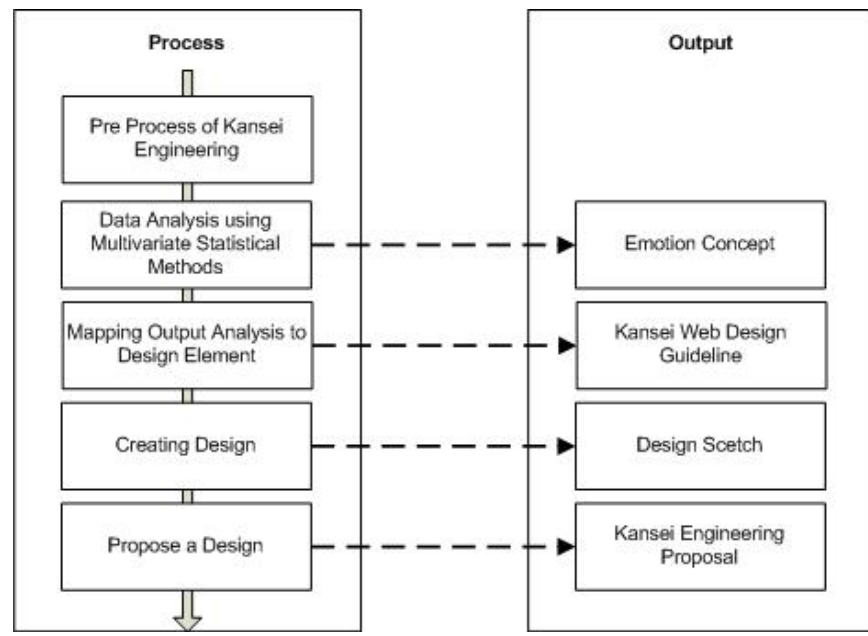

Gambar 1. Fokus Penelitian Langkah ke 5 Kansei Engineering Type I dan lebih fokus kepada Partial Least Square.

\section{PROSES PENELITIAN}

Berdasarkan Kansei Engineering Type I tahapan penelitian yang harus dilakukan adalah; pengumpulan spesimen, pengumpulan Kansei Word, pembuatan dan pengumpulan kuisioner, kemudian dilanjutkan dengan analisis statistik multivariat. Dalam penelitian ini penulis juga akan membuat alternatif hasil menggunakan salah satu cabang dari analisis statistik multivariat tersebut yaitu PLS.

\subsection{Analisis Statistik Multivariat 1) Cronbach's Alpha}

Dengan menggunakan referensi penilaian Cronbach's Alpha penulis harus memastikan bahwa data hasil kuisioner cukup valid untuk dilanjutkan menjadi analisis statistik multivariat. Cronbach's Alpha adalah metode yang digunakan untuk mengukur reliabilitas data. Seperti yang dapat terlihat pada Tabel I.

Tabel 1. Hasil Perhitungan Cronbach's Alpha

\begin{tabular}{|c|c|c|}
\hline No & Kelompok Responden & Cronbach's Alpha \\
\hline 1 & Seluruh Responden & 0.943 \\
\hline 2 & Responden Pria & 0.915 \\
\hline 3 & Respondent Wanita & 0.959 \\
\hline
\end{tabular}

Dari hasil analisis Cronbach's Alpha, keseluruhan kelompok memiliki nilai diatas 0,7 . Hal ini berarti data yang didapatkan mempunyai keandalan tinggi dan dapat digunakan untuk perhitungan analisis multivariat lebih lanjut.

\section{2) Coefficient Correlation Analysis (CCA)}

Analisis CCA digunakan untuk mengukur kekuatan hubungan antara masing-masing Kansei Word. Tabel II adalah hasil perhitungan CCA asli, hasil ini berisi 26 baris dan 26 kolom, namun pada artikel ini diringkas hanya menampilkan 20 baris dan 3 kolom yang disebabkan oleh keterbatasan ruang.

Tabel 2. Data Hasil CCA Untuk Seluruh Responden

\begin{tabular}{|c|c|c|c|c|c|}
\hline No & Variabel & 昰 & 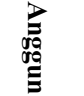 & 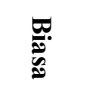 & ... \\
\hline 1 & Alami & 1 & 0.564 & -0.472 & $\ldots$ \\
\hline 2 & Anggun & 0.564 & 1 & -0.264 & $\ldots$ \\
\hline 3 & Biasa & -0.472 & -0.264 & 1 & $\ldots$ \\
\hline 4 & Canggih & 0.772 & 0.352 & -0.659 & $\ldots$ \\
\hline 5 & Ceria & 0.568 & 0.723 & -0.748 & $\ldots$ \\
\hline 6 & Feminin & 0.342 & 0.892 & -0.343 & $\ldots$ \\
\hline 7 & Formal & -0.020 & 0.148 & 0.330 & $\ldots$ \\
\hline 8 & Impresif & 0.841 & 0.569 & -0.757 & $\ldots$ \\
\hline 9 & Indah & 0.665 & 0.868 & -0.563 & $\ldots$ \\
\hline 10 & Informatif & 0.631 & 0.764 & -0.111 & $\ldots$ \\
\hline 11 & Kekanan-kanakan & 0.146 & 0.430 & -0.549 & $\ldots$ \\
\hline 12 & Keren & 0.497 & 0.674 & -0.823 & $\ldots$ \\
\hline 13 & Klasik & 0.719 & 0.550 & -0.492 & $\ldots$ \\
\hline
\end{tabular}




\begin{tabular}{|c|c|c|c|c|c|}
\hline No & Variabel & 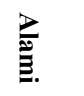 & 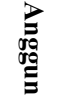 & 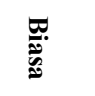 & $\ldots$ \\
\hline 14 & Kreatif & 0.470 & 0.627 & -0.814 & $\ldots$ \\
\hline 15 & Lebih Hidup & 0.686 & 0.677 & -0.838 & $\ldots$ \\
\hline 16 & Lucu & 0.594 & 0.748 & -0.668 & $\ldots$ \\
\hline 17 & Menarik & 0.601 & 0.846 & -0.678 & $\ldots$ \\
\hline 18 & Mewah & 0.428 & 0.120 & -0.581 & $\ldots$ \\
\hline 19 & Mudah Digunakan & 0.673 & 0.844 & -0.333 & $\ldots$ \\
\hline 20 & Nyaman & 0.596 & 0.909 & -0.367 & $\ldots$ \\
\hline
\end{tabular}

Bila dilihat dari Tabel 2 yang berisi informasi matriks CCA untuk seluruh responden, dapat dilihat hubungan emosional antara Kansei Words memiliki dua hubungan yaitu hubungan yang kuat dan hubungan yang lemah. Hubungan yang kuat ditandai dengan nilai tinggi pada Kansei Word. Sedangkan hubungan lemah ditandai dengan nilai negatif serta memiliki nilai mendekati 0 atau $<0,3$.

\section{3) Principal Component Analysis (PCA)}

PCA digunakan untuk mengurangi variabel data penelitian yang bernilai kecil dari Kansei Words dan spesimen[8]. PCA tidak hanya mengurangi dimensi masalah secara substansial namun juga PC yang mudah ditafsirkan secara grafis[9]. Secara subyektif dapat dikatakan bahwa kelompok spesimen yang berada di zona sumbu $\mathrm{x}$ positif adalah spesimen yang dipertimbangkan oleh responden untuk disukai. Sedangkan kelompok spesimen yang berada di zona $\mathrm{x}$ negatif adalah spesimen yang dianggap kurang disukai.

Namun, nilai output dari Principal Component Analysis (PCA) yang telah dihasilkan belum memberikan informasi yang presisi karena harus diklarifikasi dalam proses selanjutnya yaitu Factor Analysis (FA).

\section{4) Factor Analysis (FA)}

Dalam studi perilaku dan sosial, peneliti butuh pengembangan metode ukuran untuk berbagai variabel yang tidak dapat diukur secara langsung, seperti perilaku, pendapat, kecerdasan, kepribadian dan lain-lain. Factor Analysis adalah metode yang dapat digunakan untuk pengukuran tersebut[10]. Tujuan analisis faktor adalah untuk menggambarkan hubungan kovarian antara beberapa variabel yang mendasari namun tidak teramati, jumlah acak disebut faktor [11].

Factor Analysis bertujuan untuk memperkuat hasil analisis sebelumnya yang berasal dari Principal Component Analysis (PCA). Tabel 3 mengilustrasikan salah satu dari tiga hasil perhitungan FA.

Tabel 3. Perhitungan Kansei Words Berdasarkan FA Dari Responden Wanita Untuk Faktor Pertama

\begin{tabular}{|c|c|c|}
\hline No & Kansei Words & Faktor Pertama \\
\hline 1 & Biasa & -0.713 \\
\hline 2 & Penuh Sesak & -0.677 \\
\hline 3 & Sederhana & -0.151 \\
\hline 4 & Formal & -0.004 \\
\hline 5 & Informatif & 0.258 \\
\hline 6 & Mudah Digunakan & 0.311 \\
\hline 7 & Tenang & 0.379 \\
\hline 8 & Serasi & 0.393 \\
\hline 9 & Alami & 0.532 \\
\hline 10 & Anggun & 0.602 \\
\hline 11 & Nyaman & 0.630 \\
\hline 12 & Canggih & 0.716 \\
\hline 13 & Feminin & 0.717 \\
\hline 14 & Kekanak-kanakan & 0.720 \\
\hline 15 & Indah & 0.768 \\
\hline 16 & Profesional & 0.780 \\
\hline 17 & Klasik & 0.787 \\
\hline 18 & Mewah & 0.812 \\
\hline 19 & Menarik & 0.850 \\
\hline 20 & Keren & 0.864 \\
\hline 21 & Impresif & 0.868 \\
\hline 22 & Ceria & 0.871 \\
\hline 23 & Lebih Hidup & 0.872 \\
\hline 24 & Unik & 0.875 \\
\hline 25 & Lucu & 0.895 \\
\hline \multirow[t]{2}{*}{26} & Kreatif & 0.946 \\
\hline & \multicolumn{2}{|c|}{ (Creativeness) } \\
\hline
\end{tabular}

Data setelah proses pengurutan seperti terlihat pada Tabel 3 dengan nilai minimum yang digunakan lebih besar dari 0,7 namun untuk mempersempit jumlah dan fokus pada Kansei Words yang memiliki nilai pengaruh besar maka diambil nilai yang lebih besar dari 0,8 dengan Kansei Words dalam faktor pertama adalah 'Mewah', 'Menarik', 'Keren', 'Impresif', 'Ceria', 'Lebih Hidup', 'Unik', 'Lucu' dan 'Kreatif', kemudian secara subyektif Kansei Words tersebut dirangkum dalam 'Konsep Kreativitas'. Tidak seluruh data yang ditampilkan pada Tabel 3 tetapi hanya terwakili.

Semua hasil perhitungan dari PCA dan FA dari responden pria dan wanita secara subyektif diubah menjadi konsep Kansei Word seperti dapat terlihat pada Tabel 4.

Tabel 4. Hasil Konsep Emosi Dari Analisis PCA Dan FA 


\begin{tabular}{|c|c|c|c|}
\hline No & Kelompok & $\begin{array}{c}\text { Konsep } \\
\text { Kansei Word }\end{array}$ & Kansei Words \\
\hline 1 & Seluruh Responden & Coziness & Nyaman \\
\hline 2 & Responden Pria & Easiness & $\begin{array}{c}\text { Mudah } \\
\text { Digunakan }\end{array}$ \\
\hline 3 & Respondent Wanita & Creativeness & Kreatif \\
\hline
\end{tabular}

Partial Least Square atau PLS merupakan metode analisis yang handal karena dapat diterapkan pada skala data apapun, tidak membutuhkan banyak asumsi serta tidak perlu ukuran sampel yang besar. PLS dapat digunakan sebagai konfirmasi teori untuk digunakan dalam membangun hubungan yang tidak memiliki dasar teoritis atau untuk menguji proposisi. PLS juga dapat digunakan untuk memodelkan sebuah struktural dengan indikator reflektif dan formatif [12].

Pada tahap ini hasil analisis PCA dan FA adalah konsep Kansei Words yang akan diterjemahkan ke dalam elemen desain dengan menggunakan analisis Partial Least Square (PLS). Tujuan utama dari proses analisis ini adalah untuk mengetahui elemen desain yang sangat mempengaruhi emosi responden.

Tabel 5. Konsep Perancangan Gabungan Berdasarkan Kelompok Responden

\begin{tabular}{|c|l|l|}
\hline No & \multicolumn{1}{|c|}{ Kelompok } & Konsep Perancangan Gabungan \\
\hline 1 & Seluruh Responden & $\begin{array}{l}\text { Coziness digabung dengan } \\
\text { Uniqueness }\end{array}$ \\
\hline 2 & Responden Pria & $\begin{array}{l}\text { Easiness digabung dengan } \\
\text { Luxurious }\end{array}$ \\
\hline 3 & Responden Wanita & $\begin{array}{l}\text { Creativeness digabung dengan } \\
\text { Calmness }\end{array}$ \\
\hline
\end{tabular}

\subsection{Inovasi Penggabungan Kansei Words}

Sebuah analisis harus dipersiapkan dengan beberapa kemungkinan hasil dari tampilan sampel yang dapat digunakan sebagai bahan referensi desain website baru, oleh karena itu penulis mencoba menggabungkan nilai tertinggi dari konsep emosi yang dihasilkan antara faktor pertama dan faktor kedua [3]. Dari setiap kelompok responden sehingga menghasilkan konsep desain gabungan seperti yang terlihat pada Tabel 5 .

Dengan menggunakan data yang berasal dari Coefficient Correlation Analysis, Principal Component Analysis dan Factor Analysis untuk kata 'Kreatif' dan 'Tenang' yang merupakan bagian dari Kansei Words akan menghasilkan data Partial Least Square seperti yang ditunjukkan pada Tabel 6 dan Tabel 7.
Tabel 6 Hasil PLS Untuk Mencari Nilai Tertinggi Dari Kansei Word 'Kreatif' Untuk Responden Wanita Terhadap Komponen Website

\begin{tabular}{|c|c|c|c|c|}
\hline \multirow{2}{*}{ No } & \multirow{2}{*}{ Kategori } & \multicolumn{2}{|c|}{ Kreatif } & \multirow{2}{*}{$\begin{array}{r}\text { Range } \\
0.118\end{array}$} \\
\hline & & Variable & Coefficient & \\
\hline \multirow{3}{*}{1} & \multirow{3}{*}{$\begin{array}{l}\text { Left Menu } \\
\text { Background } \\
\text { Color }\end{array}$} & White & -0.017 & \multirow{3}{*}{0.233} \\
\hline & & Grey & 0.131 & \\
\hline & & Black & -0.103 & \\
\hline \multirow{3}{*}{2} & \multirow{3}{*}{$\begin{array}{c}\text { Left Menu Font } \\
\text { Color }\end{array}$} & Blue & -0.017 & \multirow{3}{*}{0.233} \\
\hline & & Black & 0.131 & \\
\hline & & Grey & -0.103 & \\
\hline \multirow{5}{*}{3} & \multirow{5}{*}{$\begin{array}{c}\text { Footer } \\
\text { Background } \\
\text { Color }\end{array}$} & Blue & 0.030 & \multirow{5}{*}{0.218} \\
\hline & & Grey & -0.044 & \\
\hline & & White & 0.119 & \\
\hline & & Black & -0.099 & \\
\hline & & None & -0.005 & \\
\hline \multirow{5}{*}{4} & \multirow{5}{*}{$\begin{array}{l}\text { Footer Font } \\
\text { Color }\end{array}$} & White & -0.053 & \multirow{5}{*}{0.209} \\
\hline & & Blue & -0.021 & \\
\hline & & Black & 0.106 & \\
\hline & & Green & 0.081 & \\
\hline & & Grey & -0.103 & \\
\hline \multirow{3}{*}{5} & \multirow{3}{*}{$\begin{array}{l}\text { Top Menu } \\
\text { Position }\end{array}$} & Left & -0.095 & \multirow{3}{*}{0.201} \\
\hline & & Center & -0.017 & \\
\hline & & Right & 0.106 & \\
\hline \multirow{4}{*}{6} & \multirow{4}{*}{$\begin{array}{c}\text { Top Menu Font } \\
\text { Color }\end{array}$} & White & -0.061 & \multirow{4}{*}{0.198} \\
\hline & & Blue & 0.009 & \\
\hline & & Black & 0.096 & \\
\hline & & Grey & -0.103 & \\
\hline \multirow{2}{*}{7} & \multirow{2}{*}{$\begin{array}{c}\text { Left Menu Font } \\
\text { Size }\end{array}$} & Small & -0.067 & \multirow{2}{*}{0.198} \\
\hline & & Medium & 0.131 & \\
\hline \multirow{3}{*}{8} & \multirow{3}{*}{$\begin{array}{c}\text { Body } \\
\text { Background } \\
\text { Color }\end{array}$} & Grey & 0.112 & \\
\hline & & White & -0.072 & 0.184 \\
\hline & & None & -0.005 & \\
\hline & & White & -0.038 & \\
\hline & & Blue & 0.023 & \\
\hline 9 & $\begin{array}{l}\text { Header Font } \\
\text { Color }\end{array}$ & Purple & 0.081 & 0.183 \\
\hline & & Black & 0.018 & \\
\hline & & Grey & -0.103 & \\
\hline 10 & Footer Logo & Left & 0.064 & 0153 \\
\hline 10 & Position & Center & -0.089 & 0.153 \\
\hline & & Small & -0.069 & \\
\hline 11 & Body Font Size & Medium & 0.069 & 0.139 \\
\hline
\end{tabular}

Tabel 7. Hasil PLS Untuk Mencari Nilai Tertinggi Dari Kansei Word 'Tenang' Untuk Responden Wanita Terhadap Komponen Website

\begin{tabular}{|c|c|c|c|c|}
\hline \multirow{2}{*}{ No } & \multirow{2}{*}{ Kategori } & \multicolumn{2}{|c|}{ Tenang } & Range \\
\cline { 3 - 5 } & & Variable & Coefficient & $\mathbf{0 . 0 8 4}$ \\
\hline 1 & Body Font Size & Small & -0.137 & 0.273 \\
\hline
\end{tabular}




\begin{tabular}{|c|c|c|c|c|}
\hline \multirow{2}{*}{ No } & \multirow{2}{*}{ Kategori } & \multicolumn{2}{|c|}{ Tenang } & \multirow{2}{*}{$\begin{array}{l}\text { Range } \\
0.084\end{array}$} \\
\hline & & Variable & Coefficient & \\
\hline & & Medium & 0.137 & \\
\hline \multirow{4}{*}{2} & \multirow{4}{*}{$\begin{array}{l}\text { Body Font } \\
\text { Color }\end{array}$} & White & 0.137 & \multirow{4}{*}{0.234} \\
\hline & & Blue & 0.001 & \\
\hline & & Black & -0.097 & \\
\hline & & Grey & 0.090 & \\
\hline \multirow{2}{*}{3} & \multirow{2}{*}{$\begin{array}{l}\text { Footer Font } \\
\text { Size }\end{array}$} & Small & -0.090 & \multirow{2}{*}{0.180} \\
\hline & & Medium & 0.090 & \\
\hline \multirow{5}{*}{4} & \multirow{5}{*}{$\begin{array}{c}\text { Footer Font } \\
\text { Color }\end{array}$} & White & 0.000 & \multirow{5}{*}{0.175} \\
\hline & & Blue & -0.107 & \\
\hline & & Black & 0.068 & \\
\hline & & Green & 0.032 & \\
\hline & & Grey & -0.045 & \\
\hline \multirow{2}{*}{5} & \multirow{2}{*}{$\begin{array}{l}\text { Footer Logo } \\
\text { Position }\end{array}$} & Left & 0.018 & \multirow{2}{*}{0.157} \\
\hline & & Center & -0.139 & \\
\hline \multirow{3}{*}{6} & \multirow{3}{*}{$\begin{array}{c}\text { Body } \\
\text { Background } \\
\text { Color }\end{array}$} & Grey & 0.094 & \multirow{3}{*}{0.141} \\
\hline & & White & -0.032 & \\
\hline & & None & -0.047 & \\
\hline \multirow{3}{*}{7} & \multirow{3}{*}{$\begin{array}{l}\text { Top Мепи } \\
\text { Position }\end{array}$} & Left & -0.064 & \multirow{3}{*}{0.130} \\
\hline & & Center & 0.001 & \\
\hline & & Right & 0.066 & \\
\hline \multirow{5}{*}{8} & \multirow{5}{*}{$\begin{array}{l}\text { Footer } \\
\text { Background } \\
\text { Color }\end{array}$} & Blue & 0.077 & \multirow{5}{*}{0.124} \\
\hline & & Grey & -0.028 & \\
\hline & & White & 0.035 & \\
\hline & & Black & -0.038 & \\
\hline & & None & -0.047 & \\
\hline \multirow{5}{*}{9} & \multirow{5}{*}{$\begin{array}{l}\text { Header Font } \\
\text { Color }\end{array}$} & White & -0.002 & \multirow{5}{*}{0.096} \\
\hline & & Blue & 0.051 & \\
\hline & & Purple & 0.032 & \\
\hline & & Black & -0.028 & \\
\hline & & Grey & -0.045 & \\
\hline
\end{tabular}

Adapun nilai range 0.118 yang berada di header Tabel 6 merupakan nilai rata-rata dari nilai range setiap kategori, adapun nilai range kategori tersebut hasil selisih dari nilai coefficient terkecil dan terbesar, begitu juga untuk nilai range 0.084 dari Tabel 7 . Kemudian dari 24 kategori yang tercantum sebelumnya di Tabel 6, kategori yang mempunyai nilai lebih kecil dari rata-rata range akan diabaikan hingga hanya mempunyai 11 kategori, begitu juga dengan Tabel 7 .

Kemudian dari data PLS yang ada di Tabel 6 dan Tabel 7 maka penulis mencoba mengurutkan kategori yang mempunyai nilai range tertinggi dan nilai coefficient variabel tertinggi akan menjadi acuan data matrik elemen HTML yang akan dikonfigurasikan sesuai pengurutan tersebut adapun data matrik tersebut terdapat dalam Tabel 8, Tabel 9, Tabel 10, Tabel 11 dan Tabel 12. Data tersebut akan menjadi acuan pembentukan elemen HTML website untuk memuaskan keinginan pengguna dalam kategori konsep desain 'Creativeness' dan 'Calmness'.
Tabel 8. Proposal Komponen Elemen Website Mobile Browser Kategori 'Body' Responden Wanita

\begin{tabular}{|c|c|c|c|c|c|c|}
\hline \multirow[b]{2}{*}{ No } & \multirow[b]{2}{*}{$\begin{array}{l}\text { Design } \\
\text { Concept }\end{array}$} & \multirow[b]{2}{*}{$\begin{array}{c}\text { Kansei } \\
\text { Words }\end{array}$} & \multicolumn{4}{|c|}{ Body } \\
\hline & & & 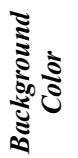 & 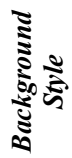 & 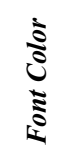 & 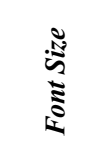 \\
\hline 1 & Creative & Kreatif & Grey & $N / S$ & $N / S$ & Medium \\
\hline 2 & Calmness & Tenang & Grey & $N / S$ & White & Medium \\
\hline
\end{tabular}

Tabel 9. Proposal Komponen Elemen Website Mobile Browser Kategori 'Top Menu' Responden Wanita

\begin{tabular}{|c|c|c|c|c|c|c|c|}
\hline \multirow[b]{2}{*}{ No } & \multirow[b]{2}{*}{$\begin{array}{l}\text { Design } \\
\text { Concept }\end{array}$} & \multirow[b]{2}{*}{$\begin{array}{l}\text { Kansei } \\
\text { Words }\end{array}$} & \multicolumn{5}{|c|}{ Тор Мепи } \\
\hline & & & ڤેั & 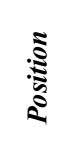 & 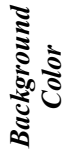 & 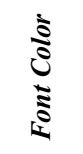 & $\begin{array}{l}\tilde{N} \\
\tilde{5} \\
\tilde{5}\end{array}$ \\
\hline 1 & Creative & Kreatif & $N / S$ & Right & $N / S$ & Black & $N / S$ \\
\hline 2 & Calmness & Tenang & $N / S$ & Right & $N / S$ & $N / S$ & $N / S$ \\
\hline
\end{tabular}

Tabel 10. Proposal Komponen Elemen Website Mobile Browser Kategori 'Left Menu' Responden Wanita

\begin{tabular}{|c|c|c|c|c|c|c|c|}
\hline \multirow[b]{2}{*}{ No } & \multirow[b]{2}{*}{$\begin{array}{l}\text { Design } \\
\text { Concept }\end{array}$} & \multirow[b]{2}{*}{$\begin{array}{c}\text { Kansei } \\
\text { Words }\end{array}$} & \multicolumn{5}{|c|}{ Left Menu } \\
\hline & & & ڤે & : & 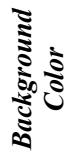 & $\begin{array}{l}\vdots \\
\vdots \\
\vdots \\
\vdots \\
\vdots\end{array}$ & 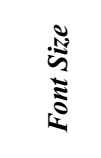 \\
\hline 1 & Creative & Kreatif & $N / S$ & $N / S$ & Grey & Black & Medium \\
\hline 2 & Calmness & Tenang & $N / S$ & $N / S$ & $N / S$ & $N / S$ & $N / S$ \\
\hline
\end{tabular}

Untuk mendapatkan nilai elemen tertinggi yang dapat dijadikan matriks usulan perancangan website mobile baru serta mempunyai perbedaan dalam hal inovasi. Proses menggabungkan Kansei Words untuk mendapatkan sampel tampilan baru, di mana dua Kansei Words dengan nilai faktor tertinggi antara F1 dan F2 dari setiap kelompok responden digabungkan dalam satu aliran proses hingga menghasilkan matriks usulan yang mempunyai nilai berbeda.

Tabel 11. Proposal Komponen Elemen Website Mobile Browser Kategori 'Header' Responden Wanita.

\begin{tabular}{|c|c|c|c|c|c|c|}
\hline \multirow[b]{2}{*}{ No } & \multirow[b]{2}{*}{$\begin{array}{c}\text { Design } \\
\text { Concept }\end{array}$} & \multirow[b]{2}{*}{$\begin{array}{c}\text { Kansei } \\
\text { Words }\end{array}$} & \multicolumn{4}{|c|}{ Header } \\
\hline & & & 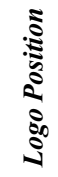 & 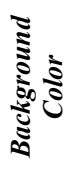 & 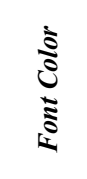 & 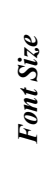 \\
\hline 1 & Creative & Kreatif & $N / S$ & $N / S$ & Purple & $N / S$ \\
\hline 2 & Calmness & Tenang & $N / S$ & $N / S$ & Blue & $N / S$ \\
\hline
\end{tabular}


Tabel 12. Proposal Komponen Elemen Website Mobile Browser Kategori 'Footer' Responden Wanita

\begin{tabular}{|c|c|c|c|c|c|c|}
\hline \multirow[b]{2}{*}{ No } & \multirow[b]{2}{*}{$\begin{array}{l}\text { Design } \\
\text { Concept }\end{array}$} & \multirow[b]{2}{*}{$\begin{array}{l}\text { Kansei } \\
\text { Words }\end{array}$} & \multicolumn{4}{|c|}{ Footer } \\
\hline & & & 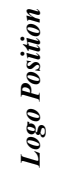 & 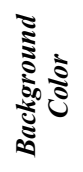 & $\begin{array}{l}\vdots \\
\vdots \\
\vdots \\
\vdots \\
0\end{array}$ & 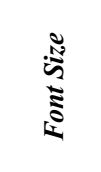 \\
\hline 1 & Creative & Kreatif & Left & White & Black & $N / S$ \\
\hline 2 & Calmness & Tenang & Left & Blue & Black & Medium \\
\hline
\end{tabular}

Selain menghasilkan contoh prototipe yang berasal dari matriks gabungan antara 'Creativeness' dan 'Calmness' seperti yang ditunjukkan pada Tabel 8, Tabel 9, Tabel 10, Tabel 11 dan Tabel 12 akan menjadi proposal elemen HTML untuk membangun desain baru, hal tersebut dapat terlihat pada Gambar 2, Gambar 3 dan Gambar 4 yang merupakan 3 (tiga) dari 9 (sembilan) hasil prototipe dari menggabungkan dua Kansei Word tertinggi dari faktor kesatu dan faktor kedua pada setiap kelompok responden wanita.

Sebuah interpretasi yang mengacu pada desain berdasarkan konsep 'Creative' yang dikombinasikan dengan konsep 'Calmness' maka akan menghasilkan interpretasi baru sebagai berikut:

Body background color disarankan menggunakan abu-abu, kemudian 'body font' disarankan menggunakan warna putih dengan ukuran font medium.

Untuk top menu style karena bernilai 'not significant' berarti tidak perlu didefinisikan secara khusus, dilanjutkan dengan posisi top menu sebelah kanan halaman website mobile dan tanpa background color karena bernilai 'not significant' dan cenderung mengikuti warna mayoritas body background image, sedangkan untuk font color menggunakan warna hitam.

Sedangkan untuk Left Menu cukup memberi warna background abu-abu, warna font hitam dan ukuran font medium.

Kategori Header untuk logo position dan background color tidak didefinisikan, sedangkan font color untuk konsep desain 'Creative' berwarna ungu dengan nilai coefficient 0.081 dan konsep desain 'Calmness' berwarna biru dengan nilai coefficient 0.051 , maka akan dipilih warna ungu dengan pertimbangan nilai coefficient yang tinggi yaitu 0.081 .

Terakhir untuk kategori footer logo position disebelah kiri dan font color berwarna hitam dengan font size medium, sedangkan untuk warna background color dengan konsep desain 'Creative' dan 'Calmness' menyarankan warna yang berbeda perlu dilihat kembali kepada rujukan dimana nilai background color untuk footer konsep 'Creative' berwarna putih dengan nilai 0.119 sedangkan untuk konsep desain 'Calmness' dengan warna biru bernilai 0.077 maka penulis menggunakan nilai tertinggi 0.119 yaitu warna putih.

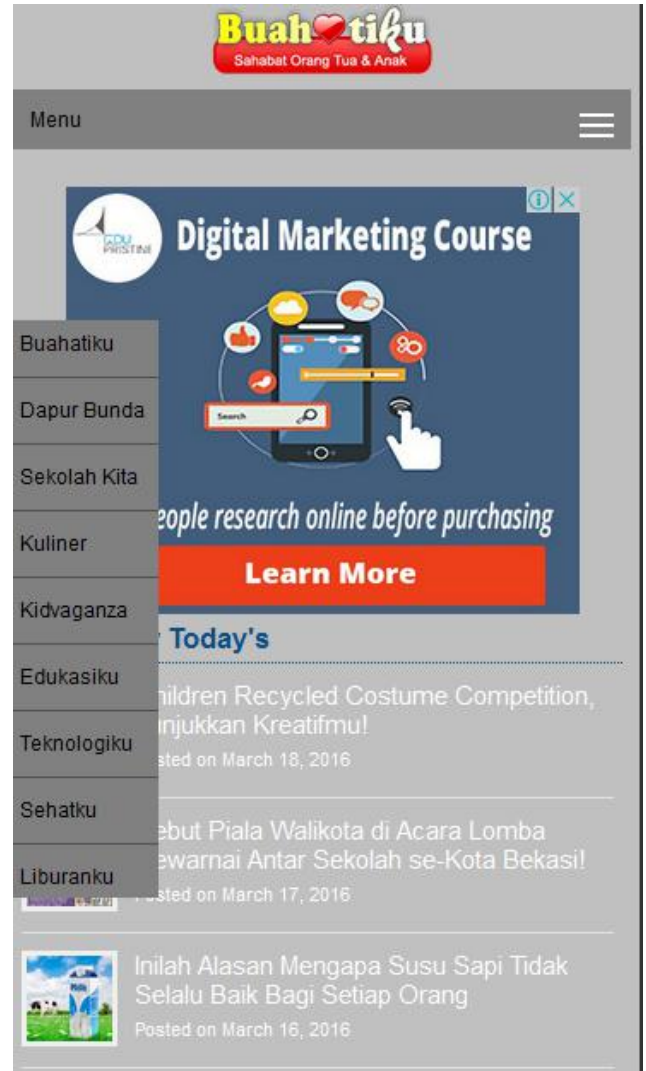

Gambar 2. Tampilan perkiraan bagian atas dari halaman website dilihat melalui mobile browser menggunakan konsep Kansei gabungan 'Creative' dan 'Calmness'

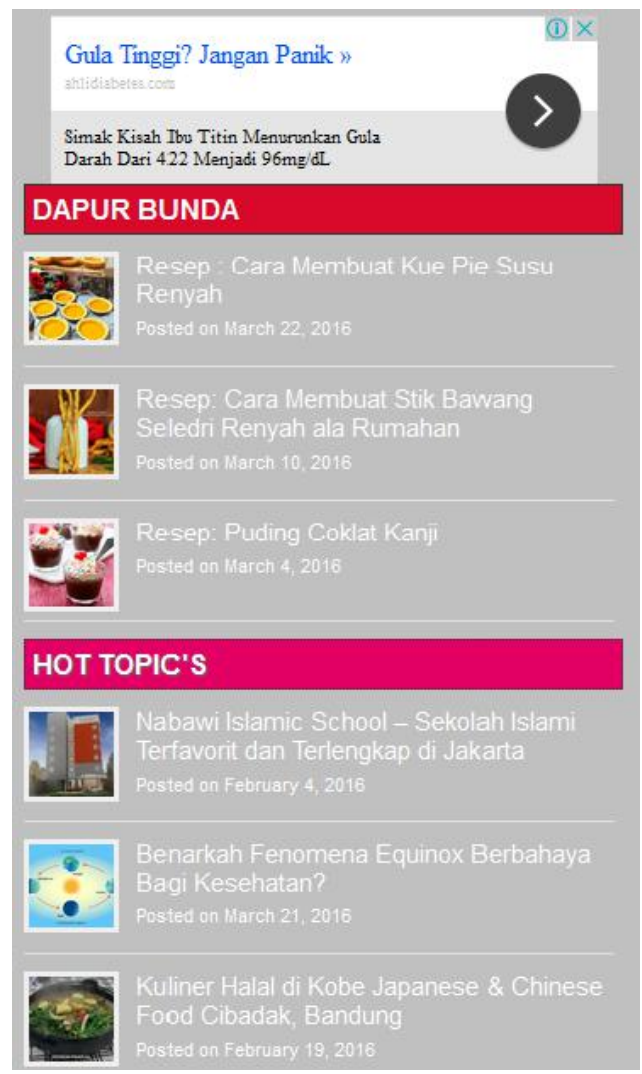

Gambar 3. Tampilan perkiraan bagian tengah dari halaman website dilihat melalui mobile browser menggunakan konsep Kansei gabungan 'Creative' dan 'Calmness' 


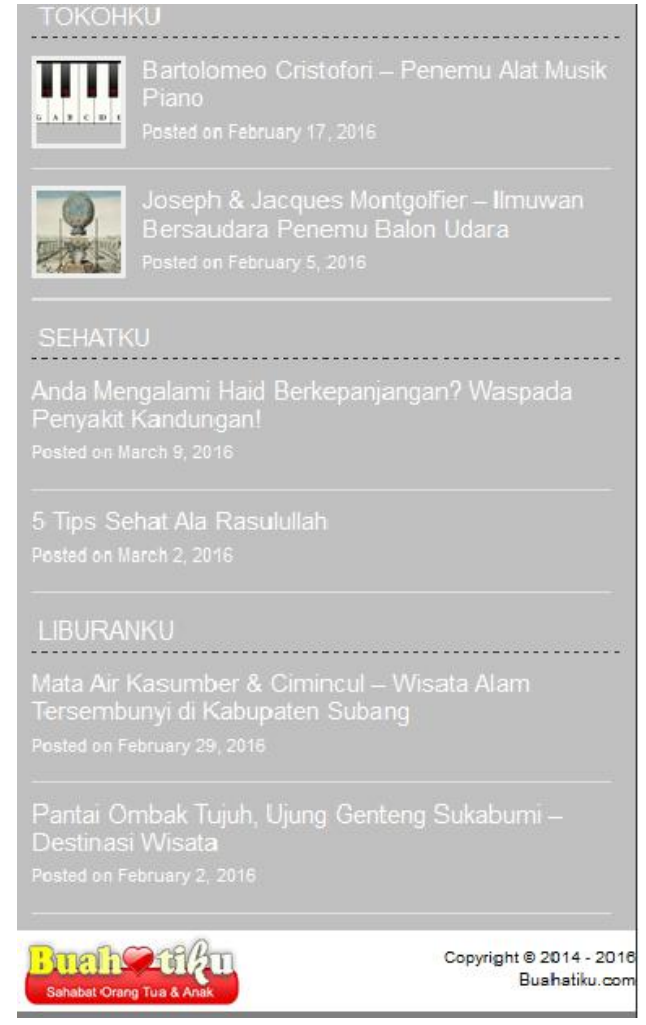

Gambar 4. Tampilan perkiraan bagian bawah dari halaman website dilihat melalui mobile browser menggunakan konsep Kansei gabungan 'Creative' dan 'Calmness'

\section{KESIMPULAN}

Penggunaan Partial Least Square untuk membantu proses Kansei Engineering dalam perancangan antarmuka website mobile browser untuk menghasilkan rekomendasi yang melibatkan faktor psikologis dan selera. Langkah Analisis Partial Least Square yang dilibatkan dalam proses analisis data untuk menerjemahkan konsep Kansei Word sehingga tidak hanya terbatas hanya menganalisa satu aspek Kansei Word tetapi lebih dari satu aspek dapat dilakukan analisa hingga dapat disimpulkan bahwa penelitian yang dilakukan telah menghasilkan:

- Partial Least Square tidak hanya dapat menganalisa satu konsep Kansei tetapi dapat juga dilakukan asimilasi lebih dari satu Kansei Words.

- Konsep desain yang telah dihasilkan dapat menjadi inovasi baru dengan melihat nilai tertinggi dari Kansei Words dari setiap konsep desain.

\section{DAFTAR PUSTAKA}

[1] Ginanjar, Arief dan Supendi, Yiyi. 2018. Implementasi Kansei Engineering Dalam Perancangan Antarmuka Website Mobile Portal Berita Informasi Pendidikan dan Kesehatan Anak., Jurnal Tiarsie., Universitas Langlangbuana., Bandung., Indonesia.

[2] Lokman, Anitawati Moch. 2009. Emotional User Experience in Web Design: The Kansei Engineering Approach. Universiti Teknologi Mara (UiTM), Malaysia.

[3] Ginanjar, Arief; Sari, Wahyu Purnama dan Herlina., 2018., Inovasi Alternatif Perancangan Tampilan Website Berdasarkan Analisis Faktor Multivariat sebagai Bagian dari Implementasi Kansei Engineering., Media Jurnal Informatika., Universitas Suryakancana., Cianjur., Indonesia.

[4] Hadiana, Ana and Ginanjar, Arief., 2018. Designing Interface of Mobile Parental Information System based on Users Perception Using Kansei Engingeering. Jorunal of Data Science adn Its Application., Telkom University., Indonesia.

[5] Haenlein, Michael and Kaplan, Andreas M. 2004. A Beginner's Guide to Partial Least Squares Analysis, Lawrence ErlBaum Associates, Inc,. New Jersey.

[6] Nagamachi. Mitsuo. et al. 2011. Innovations of Kansei Engineering. CRC Press.

[7] Lokman, Anitawati Moch., 2010, Design \& Emotion: The Kansei Engineering Methodology. Universiti Teknologi Mara (UiTM), Malaysia.

[8] Smith, Lindsay I., 2002. A tutorial on Principal Components Analysis. University of Otago, New Zealand.

[9] Jolliffe, Ian T., 2002, Principal Component Analysis, Second Edition, Springer-Verlag., New York.

[10] Sharma, S., 1996, Applied Multivariate Techniques. New Jersey: John Wiley \& Sons, Inc.

[11] Johnson, Richard A, and Dean W. Wichern., 2002, Applied Multivariate Statistical Analysis, 5th edition, Prentice Hall Inc., New Jersey.

[12] Mindrajaya, I.G.N., Sumertajaya, I.M. 2008. Pemodelan Persamaan Struktural dengan Partial Least Square. Semnas Matematika dan Pendidikan Matematika. Universitas Negeri Yogyakarta. Yogyakarta. 